\title{
Quantitative analysis on sensitive factors of runoff change in Fenhe watershed based on integration approach
}

\author{
Deng Wang, Shengqi Jian, Zening Wu, Zhaoxi Zhang, and Caihong Hu \\ College of Water Conservancy \& Environmental, Zhengzhou University. Science road 100, Zhengzhou, China \\ Correspondence: Caihong Hu (hucaihong@zzu.edu.cn)
}

Received: 30 December 2017 - Revised: 7 April 2018 - Accepted: 14 April 2018 - Published: 5 June 2018

\begin{abstract}
The runoff of the Fenhe River flowed into the Yellow River (RRY) is reducing significantly due to the influence of climate change and human activities. It is generating bad situation of shortage of water resources and led to the deterioration of ecological environment of Shanxi Province. At the same time, the reduction in RRY causes the runoff reduction in Yellow River and exacerbated the water resources shortage of the middle area of the Yellow River. Therefore, it is important to alleviate water shortage and develop the soil and water conservation measurements and regional water policy by analyzing the influence of human activities and climate change on the RRY.

The existing study quantified the reduction in amount of RRY which caused by human activities and climate change using statistical methods and watershed hydrological model. The main results of the study were as follow:

1. Using hydrological variation diagnosis system, the variation characteristics of long time series of measured annual runoff were analyzed in Hejin station that is the Fenhe River control station. The results showed that the runoff of Fenhe River run into Yellow River declined year by year, in 1971, fell the most obviously.

2. The impact of LUCC on runoff was calculated using the method of area ratio in the Fenhe River basin. Human activities were major factor in the reduction of RRY than the climate change, contributed $83.09 \%$ of the total reduction in RRY, Groundwater exploitation gave the greatest contribution to the decrease in RRY in the scope of several kinds of human activity (30.09\%), followed by coal mining (26.03\%), climate changed contributed $19.17 \%$ of the total reduction of RRY, and the decrease of precipitation contributed $20.81 \%$. But the variation of air temperature and wind speed would result in the increase of the amount of RRY.
\end{abstract}

1

The Yellow River Basin is the origin of Chinese civilization, is the second largest river after the Yangtze River, but the Yellow River Basin water shortage is extremely short, accounting for about $2 \%$ of China's runoff is about $12 \%$ of China's population production and living water, The basin's gross domestic product (GDP) accounts for $9 \%$ of the country (He et al., 2013). Zhang Xuecheng and other pointed out that the trend of runoff from Fen River Basin to the yellow river was significantly reduced, is one of the major causes of runoff reduction in the Yellow River (Zhang and Wang,
2001). However, after entering the 1970s, the measured flow of the Yellow River and its main tributaries showed a significant reduction, while the main stream and the main tributaries were repeatedly broken up (Zhang et al., 2000; Mu et al., 2007; Jia et al., 2007; Xu et al., 2012). Fenhe River is the second largest tributary of the Weihe River in the middle reaches of the Yellow River. It has an important influence on the process of water and sediment evolution in the middle and lower reaches of the Yellow River. At the same time, the Fen River is the largest river in Shanxi Province. Its basin area is $39826 \mathrm{~km}^{2}$, the basin area of $1738.7 \mathrm{mil}$ lion $\mathrm{km}^{2}$ of arable land, accounting for $30 \%$ of the total cul- 
tivated area of the province. Fenhe River is the main water source in Shanxi Province. The average annual runoff of river is 2.067 billion $\mathrm{m}^{3}$, the amount of groundwater resources is 2.50 billion $\mathrm{m}^{3}$, and the total amount of water resources is 3.358 billion $\mathrm{m}^{3}$, accounting for $27.2 \%$ of the total water resources in Shanxi Province. However, under the influence of climate change and human activities, the terrestrial water circulation pattern and water resources situation in the Fenhe River Basin have changed significantly, and a series of adverse consequences have been caused, such as the annual runoff of the Fenhe River and the decrease of the groundwater level. Especially the Fen River into the Yellow River runoff dropped, as the second largest tributary of the middle reaches of the Yellow River, Fen River into the Yellow River is the middle reaches of the Yellow River water resources, an important source of supply, Fen River runoff dropped, not only increased the Fen River Basin water Resources supply and demand contradiction, but also to the middle and lower reaches of the Yellow River can be a significant reduction in water resources, increased between the provinces and the water sector water distribution work difficult. In addition, the decrease of runoff of the Yellow River caused by the decrease of the runoff of the Fenjiang River has a significant impact on the river bed evolution in the middle and lower reaches of the Yellow River, which has caused the Yellow River main channel to shrink further and thus adversely affect the river health of the Yellow River. Yuan Zhihua's study shows that (1950-2005) into the the Yellow River Fenhe River runoff reduction, human activities are the main factors leading to the decrease of runoff in the Fenhe River Basin, runoff reduction accounted for $75.9 \%$ of the total reduction of runoff (Yuan et al., 2008); Wang Guoqing on the impact of environmental change on Runoff in the Fenhe River Basin using SIMHYD conceptual rainfall runoff model, the results of the study indicate that on average, 1970-1999 years, the impact of climate factors and human activities on runoff accounted for $35.19 \%$ of the total reduction of runoff and $64.11 \%$, human activities are the main factors of Fenhe River Runoff reduction (Wang et al., 2008).

There are four methods to evaluate the hydrological effects of environmental changes: similar watershed comparative test, hydrological model simulation, sensitivity analysis based on hydrothermal coupled equilibrium equation and statistical regression analysis (Li et al., 2009). Similar watershed comparison test method is to select two experimental conditions with similar climatic conditions, topography, area and other characteristics. Under the same gradient and climatic conditions, change the climatic conditions of another experimental basin or the watershed characteristics, the differences between hydrological variables in these two experimental watersheds analyze the impact of human activities on hydrological processes in the basin. However, this method has limitations in the watershed scale for high cost and difficult to find similar watershed (Zhao et al., 2010). Statistical regression analysis is based on the analysis of hydrological and meteorological data using statistical principles. Through the analysis of the factors influencing the process of runoff formation, the main influencing factors of runoff variation are established, and the regression equation of runoff and main influencing factors is established. The advantages of the method are relatively easy to implement, but do not reflect the nonlinear relationship between rainfall and runoff (Ahn and Merwade, 2014), and the accuracy of the results is not high (Jiang et al., 2011). Sensitivity analysis is mainly used to quantitatively analyze the impact of climate change on runoff, which evaluates the impact of climate change on runoff by determining the degree of change in the runoff of the basin due to changes in the climate factors of the unit, and is widely used in quantitative analysis of environmental change Runoff effects, and achieved satisfactory results (Wang et al., 2013; Elfert and Bornmann, 2010; Awan and Ismaeel, 2014; Ahn and Merwade, 2014; Zeng et al., 2014). Based on the understanding of hydrological phenomena, the hydrological model of watershed through establishes a hydrological model by mathematical method to analyzes its causes and the relationship between hydrological elements, and. With the development of computer and GIS technology, hydrological model method has become a powerful tool to study hydrological problems (Awan and Ismaeel, 2014; Ahn and Merwade, 2014; Li et al., 2009). Although the impact of climate change and human activities on runoff, domestic and foreign scholars have done a lot of research and determine the very rich results, there are still some problems: Most research of the impact of the quantitative analysis of climate change and human activities on runoff research, only take the factors that impact runoff changes as climate factors and human factors, and on this basis, quantitative analysis the impact of both changes in runoff, the impact of human activities to the next level, a detailed division of the various climate and human activities on runoff is not included.

According to the available data, the main factors influencing the runoff in the Fenhe River Basin are: the annual rainfall of the Fenhe River Basin is reduced by $38800 \mathrm{~m}^{3}$ per year from 1956 to 2012. The potential evapotranspiration of the Fenhe River Basin shows a decreasing trend. The average annual growth rate of surface water in the Fenhe River Basin increased to 18.06 million $\mathrm{m}^{3}$ per year in between 1980 and 2012, the water supply in the Fenhe River Basin accounted for The total amount of water supply was $63 \%$; With the development of economy, the amount of coal mining increased year by year, especially in the 20th century After the age of 1991, the province's total output of 288.57 million t, to 1993 exceeded 300 million t, the highest in 1996 to 34.9460 million t, the subsequent mining volume gradually reduced in 2000 to 246114500 t; so far, Fen River (61), including the large and medium-sized reservoirs 17 , the total control basin area of $14736 \mathrm{~km}^{2}$; small (I) and small (II) type of reservoirs 165 , the total storage capacity of 17.2016 billion $\mathrm{m}^{3}$, Total control basin area $15317 \mathrm{~km}^{2}$; as of the end of 2006, Fenhe River Basin soil and water conser- 
vation measures accumulated area of $22230 \mathrm{~km}^{2}$, of which terraced fields (including beach and dry plains) $4970 \mathrm{~km}^{2}$, water conservancy and forestry forest $11800 \mathrm{~km}^{2}$, economic forest $1595 \mathrm{~km}^{2}$, grassland $830 \mathrm{~km}^{2}$, dam $58800 \mathrm{~km}^{2}$, and another closed hillside area of $245000 \mathrm{~km}^{2}$. The exploitation of surface water affects the runoff of the surface water by the increase or decrease of surface water consumption. The groundwater exploitation affects the runoff through the groundwater consumption and the amount of submerged water. The water conservancy project affects the regional runoff through the increase or decrease of the regional evaporation and the soil and water conservation measures change the land use type area to affect runoff. Therefore, based on the principle of water balance, this paper constructs a unified framework for the reduction of gravity flow into the Yellow River. In this framework, different methods are used to quantitatively analyze the changes of rainfall, the change of potential evapotranspiration, Groundwater exploitation, coal mining, water conservancy projects and soil and water conservation measures on the Fen River into the yellow runoff rate of contribution. The purpose of this paper is as follows: (1) Analyze the trend of runoff change in Fenhe River Basin during 1956-2012 and analyze the factors influencing the change. (2) Quantitative analysis of the contribution of climate change and river basin attribute change to runoff changes.

\section{Materials and methods}

\subsection{Overview of the study area}

Fenhe River Basin is located at $110.5-113.5^{\circ}$ E, 35.3$39.0^{\circ} \mathrm{N}$, the terrain is north high, south low, longitudinal watershed topography is north-south length $413 \mathrm{~km}, 188 \mathrm{~km}$ long from east to west. The elevation of the basin continues to decline, and the elevation of the mountains on both sides of the east and west increases, resulting in a disparity in the height of the ground, and the transitional zone between the valley basin and the mountain is the loess plateau. Watershed landforms can be divided into three types of area: loess hilly and gully region, rocky mountainous area and river channel area. The total area of the river basin is 39471 square kilometers (Fig. 1), accounting for $5.2 \%$ of the Yellow River basin area, which is the second largest tributary of the Yellow River and the main source of the runoff of the Yellow River (Du and Zhang, 2016).

Fenhe River Basin belongs to mid latitude continental monsoon climate, the climate is characterized by four distinctive seasons: short day and little rain and more sand wind in spring (Liang et al., 2010), high temperature and more rainstorm in summer, the difference in start time is more, mild and sunny in autumn, scarce precipitation and cold and dry in winter. The basin is rich in light and heat resources, lack of water resources. The average temperature of Fenhe River Basin changed from 13 to $4{ }^{\circ} \mathrm{C}$ between south and

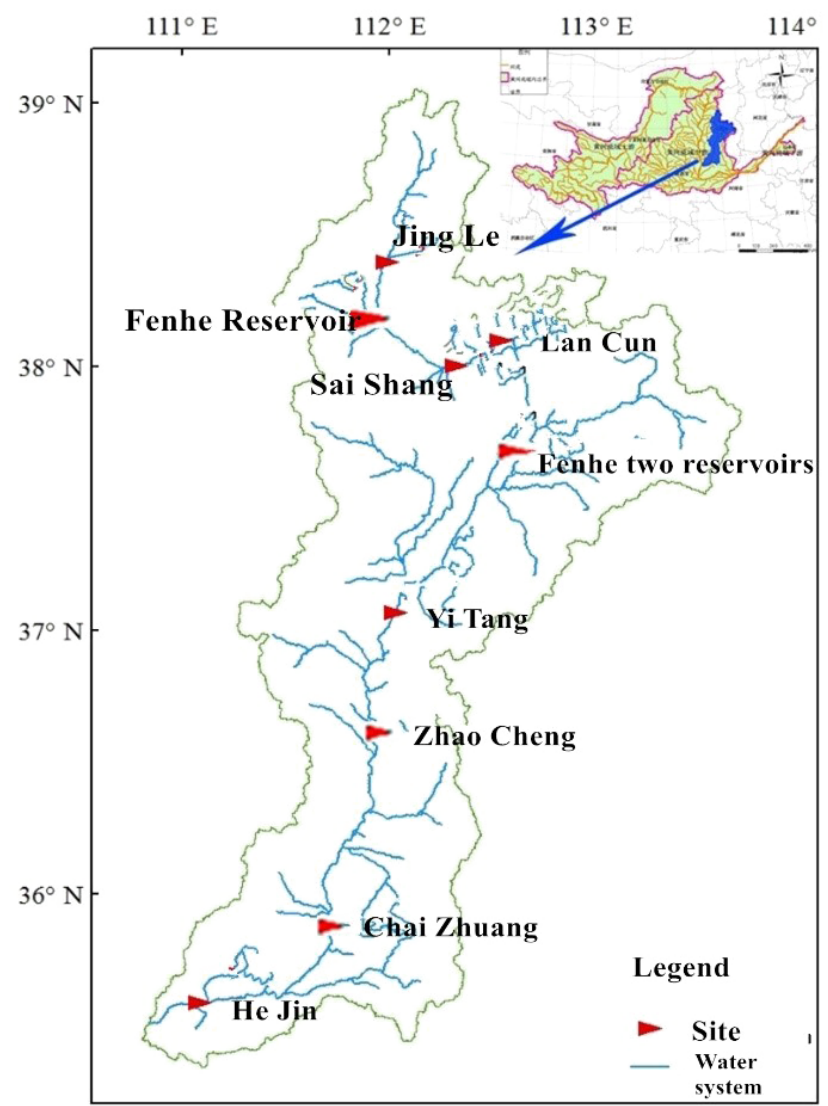

Figure 1. Fenhe River Basin.

north, and frost-free period was 80-205 days, which also showed a decreasing trend from south to north.

The nine hydrological stations on Fenhe River, from upstream to downstream be: Jingle, Fenhe Reservoir, Zhaishang, Lanchun, Erba, Yitang, Zhaocheng, Chaizhuang and Hejin. Among them, the Hejin Station is the Fenhe entering Yellow River control station, whose control basin area is 38728 square kilometers, accounting for $98 \%$ of the total area of Fenhe River basin.

The average precipitation in the Fenhe River Basin (19562012 series) is $503 \mathrm{~mm}$, and the distribution of precipitation is decreasing from the southeast to the northwest, but it is closely related to the terrain elevation. The warm and humid airflow brought by the summer monsoon is the main source of water vapor for precipitation. Precipitation from June to September accounts for more than $70 \%$ of the total annual precipitation.

\subsection{Data selection}

This study collected the annual runoff from 1956 to 2012 in the Fen River Basin into the Yellow Control Station (Hejin station), and the rainfall data from 1956 to 2012 in the Fenhe River Basin. The meteorological data of the $10 \mathrm{ma}-$ 
jor weather stations in the basin (Hejin, Jiexiu, Lok, Linfen, Qixian, Qingxu, Taigu, Taiyuan and Yicheng) from 1956 to 2012 including mean daily wind speed, daily average temperature, daily maximum temperature, daily minimum temperature, sunshine hours, relative humidity and daily mean vapor pressure. At the same time, the data of surface water consumption, the results of soil and water conservation measures in Fenhe River Basin, the data of human water consumption, the data of water conservancy construction and the data of coal mining were collected. Runoff data and rainfall data were collected from the Hydrological Bureau of the Ministry of water resources compiled by the hydrological data series of the Yellow River. Meteorological data from China Meteorological Data network.

In addition, this study also collected the Fenhe River Basin groundwater depth data in Fenhe River Basin in 2001-2012, which include a total of 199 groundwater depth monitoring station (Fig. 2), It can be seen from the figure that the Fenhe River Basin groundwater depth monitoring stations in this study are concentrated in Taiyuan and Linfen basins. The soil data of the Fen River basin in this paper are derived from the HSWD soil database (Fig. 3) constructed by the International Food and Agriculture Organization (FAO), and the soil classification is FAO-90. And the obtain data is correct by the reference to "Shanxi Soil" edited by Liu Yaosong.

\subsection{Methods}

Based on the analysis of the characteristics of measured annual runoff of Hejin River in Hejin River Basin, the main climatic and human influencing factors of Fenhe River entering the Yellow River runoff were determined. Based on the annual variation of annual runoff of Hejin River. The measured annual runoff of Hejin station is divided into two periods: "basis period" and "change period", the difference between the mean measured annual runoff of "base period" and "change period" is the total reduction, The total reduction in the Fen River into the Yellow River runoff includes the reductions caused by climate change and the reductions caused by major human activities. On the basis of estimating the total reduction of the Yellow River runoff from the Fen River, a unified framework for the reduction of the diameter of the Fenhe River into the Yellow River is established. In this framework, the separation and evaluation of the effects of climate change and main human activities on runoff are as follows (Wang et al., 2008):

$$
\begin{aligned}
& \Delta W=W_{\mathrm{hc}}-W_{\mathrm{b}} \\
& \Delta W=\Delta W_{\mathrm{c}}+\Delta W_{\mathrm{hum}} \\
& \Delta W_{\mathrm{c}}=\Delta W_{\mathrm{p}}+\Delta W_{E_{0}} \\
& \Delta W_{\mathrm{hum}}=\Delta W_{\mathrm{wc}}+\Delta W_{\mathrm{gw}}+\Delta W_{\mathrm{wcp}}+\Delta W_{\mathrm{coal}}+\Delta W_{\mathrm{LUCC}} \\
& \eta_{\mathrm{p}}=\frac{\Delta W_{\mathrm{p}}}{\Delta W} \times 100 \% \\
& \eta_{E_{0}}=\frac{\Delta W_{E_{0}}}{\Delta W} \times 100 \%
\end{aligned}
$$

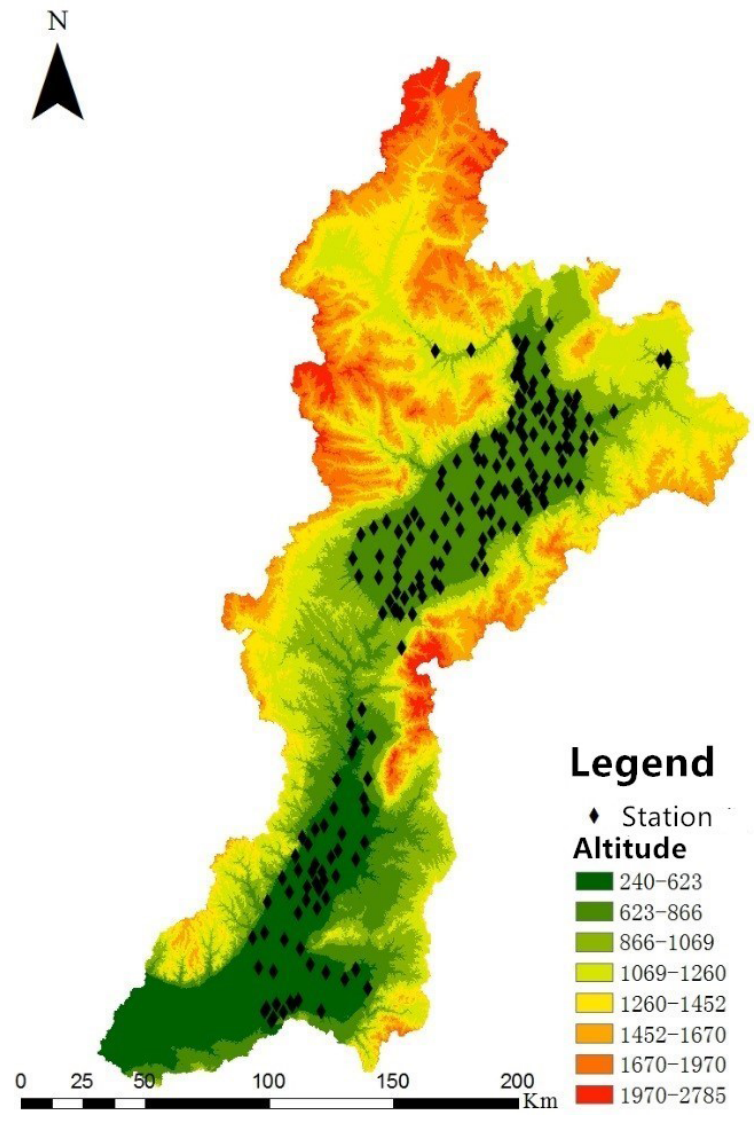

Figure 2. Distribution of Groundwater Level and Buried Survey in Fenhe River Basin.

$$
\begin{aligned}
& \eta_{\mathrm{c}}=\eta_{\mathrm{p}}+\eta_{E_{0}} \\
& \eta_{\mathrm{wc}}=\frac{\Delta W_{\mathrm{wc}}}{\Delta W} \times 100 \% \\
& \eta_{\mathrm{gw}}=\frac{\Delta W_{\mathrm{gw}}}{\Delta W} \times 100 \% \\
& \eta_{\mathrm{wcp}}=\frac{\Delta W_{\mathrm{wcp}}}{\Delta W} \times 100 \% \\
& \eta_{\mathrm{coal}}=\frac{\Delta W_{\mathrm{coal}}}{\Delta W} \times 100 \% \\
& \eta_{\mathrm{LUCC}}=\frac{\Delta W_{\mathrm{LUCC}}}{\Delta W} \times 100 \% \\
& \eta_{\text {hum }}=\eta_{\mathrm{wc}}+\eta_{\mathrm{gw}}+\eta_{\mathrm{wcp}}+\eta_{\mathrm{coal}}+\eta_{\mathrm{LUCC}}
\end{aligned}
$$

In the formula, $\Delta W$ is the total reduction of the Yellow River runoff into the Yellow River, the unit is $10^{8} \mathrm{~m}^{3} ; W_{\mathrm{hc}}$ is the measured annual flow rate of change, the unit is $10^{8} \mathrm{~m}^{3} ; W_{\mathrm{b}}$ is the base year measured annual runoff, the unit is $10^{8} \mathrm{~m}^{3}$; $\Delta W_{\mathrm{c}}$ is the amount of runoff reduction caused by climate change, the unit is $10^{8} \mathrm{~m}^{3} ; \Delta W_{\text {hum }}$ is the amount of runoff reduction caused by human activity, the unit is $10^{8} \mathrm{~m}^{3} ; \Delta W_{\mathrm{p}}$ is the amount of runoff reduction caused by reduced rainfall, the unit is $10^{8} \mathrm{~m}^{3} ; \Delta W_{E_{0}}$ is the amount of runoff reduction caused by the decrease in potential evapotranspiration, 


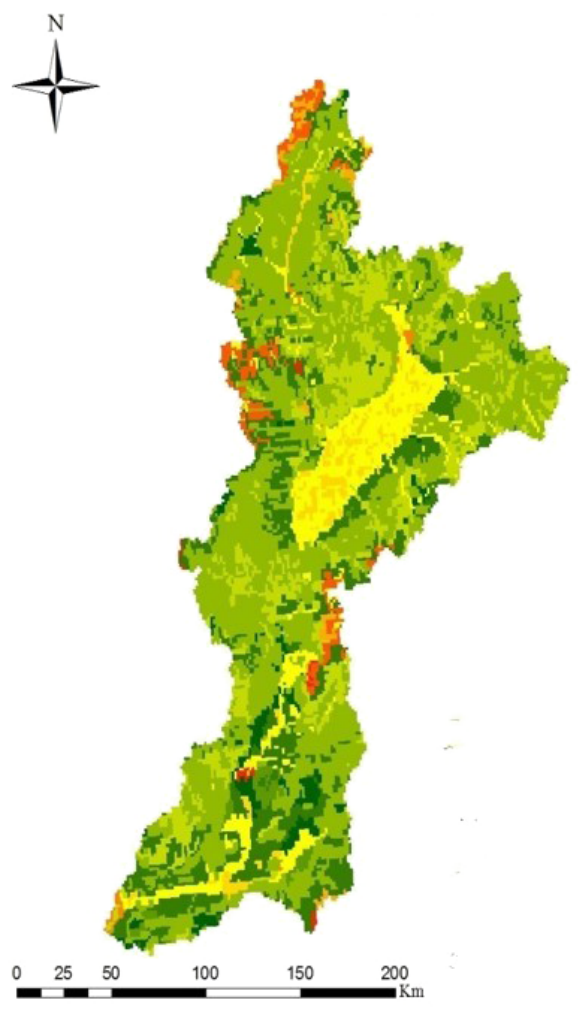

Figure 3. Distribution of Soil Types in Fenhe River Basin.

the unit is $10^{8} \mathrm{~m}^{3} ; \Delta W_{\mathrm{wc}}$ is the amount of runoff reduction caused by the increase in surface water consumption, the unit is $10^{8} \mathrm{~m}^{3} ; \Delta W_{\mathrm{gw}}$ is the amount of runoff reduction caused by groundwater exploitation, the unit is $10^{8} \mathrm{~m}^{3} ; \Delta W_{\text {wcp }}$ is the amount of runoff reduction caused by the new evaporation of water conservancy projects, the unit is $10^{8} \mathrm{~m}^{3} ; \Delta W_{\text {coal }}$ is the amount of runoff reduction caused by coal mining, the unit is $10^{8} \mathrm{~m}^{3} ; \Delta W_{\text {LUCC }}$ is the amount of runoff reduction caused by land use change, the unit is $10^{8} \mathrm{~m}^{3} ; \eta_{\mathrm{p}}, \eta_{E_{0}}, \eta_{\mathrm{wc}}, \eta_{\mathrm{gw}}$, $\eta_{\text {wcp }}, \eta_{\text {coal }}, \eta_{\text {LUCC }}, \eta_{\mathrm{c}}, \eta_{\text {hum }}$ are the contribution rate of rainfall, potential evapotranspiration, surface water consumption, groundwater exploitation, water conservancy projects, coal mining, land use, climate change and human activities to the Yellow River.

\subsubsection{Runoff sequence diagnosis method}

The hydrological variation diagnostic system takes into account both the trend and the jumping of two variants (Xie et al., 2010). The basic idea is to use a variety of mutation test methods to diagnose the hydrological sequence in detail on the basis of the possibility of preliminary test, and to obtain the efficiency coefficient of the trend and jump diagnosis conclusion, then the degree of fitting of the hydrological sequence to the jumping component or trend component is evaluated according to the efficiency coefficient. According

\section{Legend}

Saturated rudiment soil
Soft shallow soil
Saturated loose rocky soil
Calcareous soil
Calcareous loose rocky soil
$\square$ Lime alluvial soil
Rock alluvial soil
Unsaturated soil
Water body
Weak development of leaching soil
Calcareous leaching soil

to the actual hydrological investigation and analysis, the variant forms and conclusions were verified, and the final diagnosis results were obtained. The system can solve the problem that the test result of the single method is not reasonable and the results of various methods are inconsistent.

\subsubsection{Calculation method of potential evapotranspiration}

Based on the 10 weather station data, the basin's potential evapotranspiration from 1956 to 2012 was calculated using the Penman-Monteith formula recommended by the International Food and Agriculture Organization (FAO) (Pereira et al., 2015), as shown in the following equation. At the same time collected and compiled from 1956 to 2012 reservoir, water supply, land use and coal mine data.

$$
\mathrm{ET}_{0}=\frac{0.408 \Delta\left(R_{\mathrm{n}}-G\right)+\gamma \frac{900}{T_{\text {mean }}+273} U_{2} \cdot\left(\mathrm{VP}_{\mathrm{s}}-\mathrm{VP}\right)}{\Delta+\gamma\left(1+0.34 U_{2}\right)}
$$

where $\mathrm{ET}_{0}$ is the potential evaporation, $\mathrm{mm} \mathrm{d}^{-1} ; R_{\mathrm{n}}$ is the net radiation, $\mathrm{MJ} /\left(\mathrm{m}^{2} \mathrm{~d}\right) ; G$ is the soil heat flux $\mathrm{MJ} /\left(\mathrm{m}^{2} \mathrm{~d}\right) ; \gamma$ is the wet and dry constant, $\mathrm{kPa} /^{\circ} ; \Delta$ is the saturation water vapor pressure curve slope, $\mathrm{kPa} /{ }^{\circ} ; U_{2}$ is $2 \mathrm{~m}$ high wind speed, $\mathrm{m} \mathrm{s}^{-1}$; VPs are the average saturated vapor pressure, $\mathrm{kPa}$; VP is the actual vapor pressure $\mathrm{kPa} ; T_{\text {mean }}$ is the average temperature, ${ }^{\circ}$. Net radiation is the sum of solar shortwave radiation 


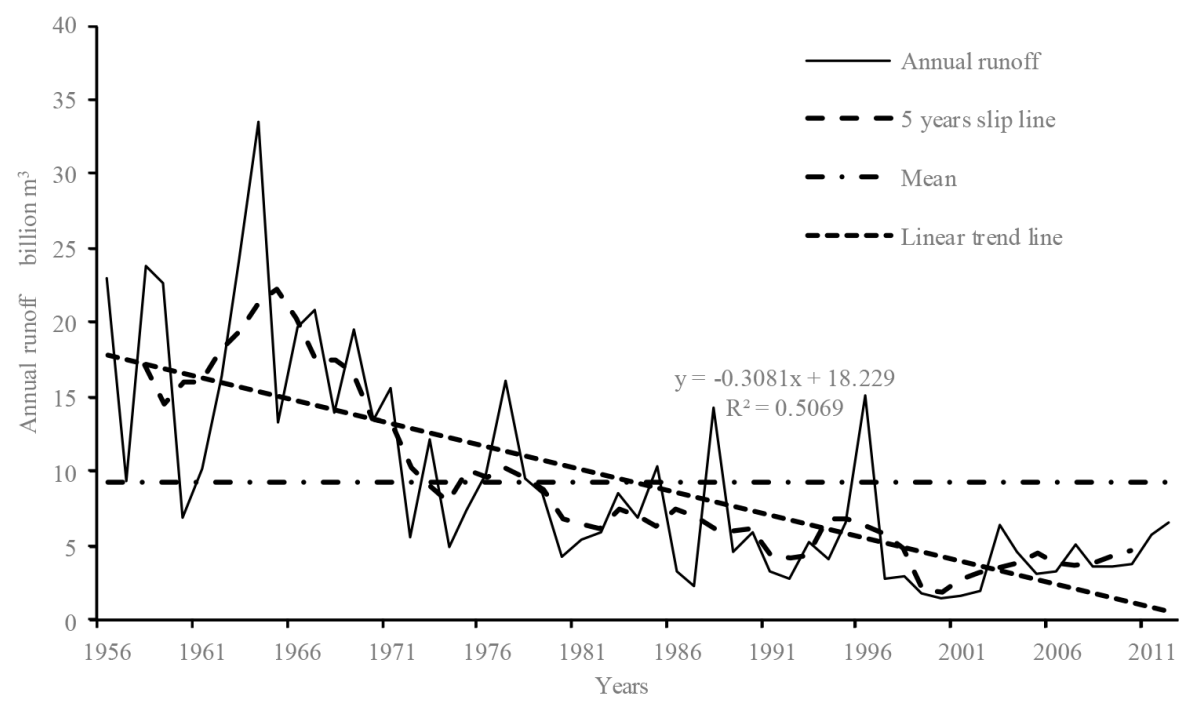

Figure 4. Trend of annual average runoff in Hejin station.

Table 1. The results of runoff diagnosis in Hejin station.

\begin{tabular}{lllr}
\hline Project & Critical result & Project & Critical result \\
\hline Hurst coefficient & 0.914 & Jumping comprehensiveness & $4(+)$ \\
Overall degree of variation & Strong variation & Trends comprehensiveness & $3(+)$ \\
Trend of variation & Trend strong variation & Jump efficiency coefficient & 52.22 \\
Jumping point & 1971 & Trend efficiency coefficient & 36.72 \\
Jumping comprehensive weight & 0.69 & Diagnosis conclusion & $1971(+) \downarrow$ \\
\hline
\end{tabular}

Notes: 1971(+) $\downarrow$ indicates a significant decrease in the sequence in 1971

and ground longwave radiation, where solar radiation can be estimated as follows:

$R_{\mathrm{S}}=\left(a_{\mathrm{s}}+b_{\mathrm{s}} \frac{n}{N}\right) R_{\mathrm{a}}$

where $R_{\mathrm{S}}$ is the solar radiation $\left(\mathrm{W} \mathrm{m}^{-2}\right) ; R_{\mathrm{a}}$ is the solar radiation of the top floor of the atmosphere $\left(\mathrm{W} \mathrm{m}^{-2}\right) ; a_{\mathrm{s}}$ and $b_{\mathrm{s}}$ are the parameters, where $a_{\mathrm{s}}=0.25, b_{\mathrm{s}}=0.5$.

\subsubsection{Quantitative analysis method of influence of climate change on Runoff}

The change of annual rainfall and potential evaporation will lead to the change of water balance, Koster (Koster et al., 1999) and Milly (Milly and Dunne, 2002) give the calculation formula of the change of runoff caused by the change of annual rainfall and potential evaporation in the basin:

$$
\begin{aligned}
& \Delta W_{\mathrm{c}}=\varepsilon_{P} \frac{\bar{R}}{\bar{P}} \Delta P+\varepsilon_{E_{0}} \frac{\bar{R}}{\overline{E_{0}}} \Delta E_{0} \\
& \Delta W_{P}=\varepsilon P \frac{\bar{R}}{\bar{P}} \Delta P \\
& \Delta W_{E_{0}}=\varepsilon_{E_{0}} \frac{\overline{\bar{R}}}{\overline{E_{0}}} \Delta E_{0}
\end{aligned}
$$

where $\bar{R}$ is the base year multi-year average runoff depth, $\mathrm{mm} ; \bar{P}$ is the average annual rainfall for the base period, $\mathrm{mm} ; \overline{E_{0}}$ is the basis of the average annual number of potential evaporation, $\mathrm{mm} ; \Delta P$ is the difference between the average rainfall of the base period and the change period, $\mathrm{mm}$; $\Delta E_{0}$ is the difference between the average potential evaporation of the base period and the change period, $\mathrm{mm} ; \varepsilon$ pis the precipitation elasticity coefficient, $\varepsilon_{E_{0}}$ is the potential evapotranspiration elasticity coefficient. When the climate elasticity coefficient is used to quantitatively calculate the effect of climate change on runoff, the calculation method of the two elastic elastic coefficients has a great influence on the result and requires the underlying surface parameter $\omega$. Sankarasubramanian (Sankarasubramanian and Vogel, 2001) gives a nonparametric method for calculating the elasticity of climate:

$\varepsilon_{X}=\frac{\bar{X}}{\bar{R}} \cdot \frac{\left(X_{i}-\bar{X}\right)\left(R_{i}-\bar{R}\right)}{\sum\left(X_{i}-\bar{X}\right)^{2}}$

where $X$ is the climatic factor. Based on the results of comparison of various climatic elasticity coefficients, it is found that the nonparametric calculation method of climate elasticity coefficient is reliable. 
Table 2. Calculation results of impacts of climate change on inlet runoff in Fenhe River Basin.

\begin{tabular}{lrrrcrrrrr}
\hline Time & $\begin{array}{r}\bar{R} \\
(\mathrm{~mm})\end{array}$ & $\begin{array}{r}\bar{P} \\
(\mathrm{~mm})\end{array}$ & $\begin{array}{r}\overline{E_{0}} \\
(\mathrm{~mm})\end{array}$ & $\varepsilon_{P}$ & $\varepsilon_{E_{0}}$ & $\begin{array}{r}\Delta P \\
(\mathrm{~mm})\end{array}$ & $\begin{array}{r}\Delta E_{0} \\
(\mathrm{~mm})\end{array}$ & $\begin{array}{r}\Delta W_{P} \\
(\mathrm{~mm})\end{array}$ & $\begin{array}{r}\Delta W_{E_{0}} \\
(\mathrm{~mm})\end{array}$ \\
\hline $1956-1971$ & 45 & 541 & 969 & 1.491 & -0.331 & -55 & -35 & -6.89 & 0.55 \\
$1980-2012$ & 13 & 486 & 933 & & & & & & \\
\hline
\end{tabular}

Table 3. The relative contribution of the factors affecting the natural runoff in the Fenhe River Basin from 1980 to 2012.

\begin{tabular}{clrr}
\hline & Influencing factors & $\begin{array}{r}\text { Influence quantity } \\
\left(\text { Billion } \mathrm{m}^{3}\right)\end{array}$ & $\begin{array}{r}\text { Contribution rate } \\
(\%)\end{array}$ \\
\hline \multirow{2}{*}{ Climate } & -2.67 & -20.81 \\
& Rainfall & 0.21 & 1.64 \\
\cline { 2 - 3 } & Temperature, wind speed and so on & -2.46 & -19.17 \\
\hline \multirow{2}{*}{ Humabtotal } & Surfacewater exploitation & -2.32 & -19.17 \\
& Groundwater exploitation & -3.86 & -30.09 \\
& Water Conservancy Project & -0.09 & -0.07 \\
& Land use & -1.05 & -8.18 \\
& Coal mining & -3.34 & -26.03 \\
\hline \multirow{2}{*}{ Subtotal } & -10.66 & -83.09 \\
\hline
\end{tabular}

\subsubsection{Quantitative Analysis Methods for the Impact of Human Activities on Runoff}

The exploitation of surface water affects the runoff of the surface water by the increasing or decreasing of surface water consumption. The groundwater exploitation affects the runoff through the groundwater consumption and the amount of submerged water. The water conservancy project affects the regional runoff and the soil and water conservation measures through the increase or decrease in the regional evaporation Change the land use type area to affect runoff. Therefore, this paper uses the sub-calculation method to calculate the impact of various human activities on the Fen River runoff.

\section{Results}

\subsection{Runoff trends and variation analysis}

Showing in Fig. 4 is the Hejin station 1956-2012 runoff trends and 5-year sliding map. It can be seen that the annual runoff from 1956 to 2012 is 994 million $\mathrm{m}^{3}$, and the runoff is obviously decreasing. Before the 1980s, the runoff was above the mean line, and most of the runoff was below the mean in the 1980s, only in 1988 and 1996, the runoff was greater than the mean.

On the basis of preliminary diagnosis, three flow diagnosis methods of three trend diagnosis methods and 11 jump diagnosis methods were used to determine the flow rate of Hejin station. The first significant $\alpha=0.05$ and the second significant $\beta=0.01$ were analyzed. The diagnostic results are shown in Table 1. It can be seen from Table 1 that the runoff mutation period of Hejin station is 1971, and there is a significant downward trend. The trend and variation are significant. The variation efficiency coefficient is larger, indicating that the variation is strong. In conclusion, the runoff of Hejin station showed a significant decrease trend, and the mutation occurred in 1971. Before 1971, the average annual runoff was 1.793 billion $\mathrm{m}^{3}$. After 1971, the annual runoff was 9.44 billion $\mathrm{m}^{3}$, and the annual runoff was significantly changed. From the analysis of the hydrological variation diagnostic system, the runoff in the 1956-2012 years of the Hejin Railway Station showed a downward trend and a sudden change in 1971, which was consistent with the results of Zhao et al. (2012).

Figure 5 shows the relationship between rainfall runoff and anomaly in Hejin station. It can be seen from Fig. 5a that the rainfall-runoff relationship in the basin has changed significantly before and after 1971, and the rainfall-runoff curve after 1971 shows that the runoff generated by 1971 Before 1971. It can be seen from Fig. 5b that the change of rainfall sequence is relatively stable, which is basically positive and negative alternately, and the runoff is basically positive anomaly before the 1970 s, and it is basically negative anomaly after the 1970s, The At the same time, before and after the mutation, the precipitation is mainly between $306 \mathrm{~mm}$ and $652 \mathrm{~mm}$, and the change trend of the precipitation sequence is not obvious. According to the runoff forming mechanism, we judge that the underlying land surface condition in the basin must change. This result is confirmed by some factual data collected in the introduction. 

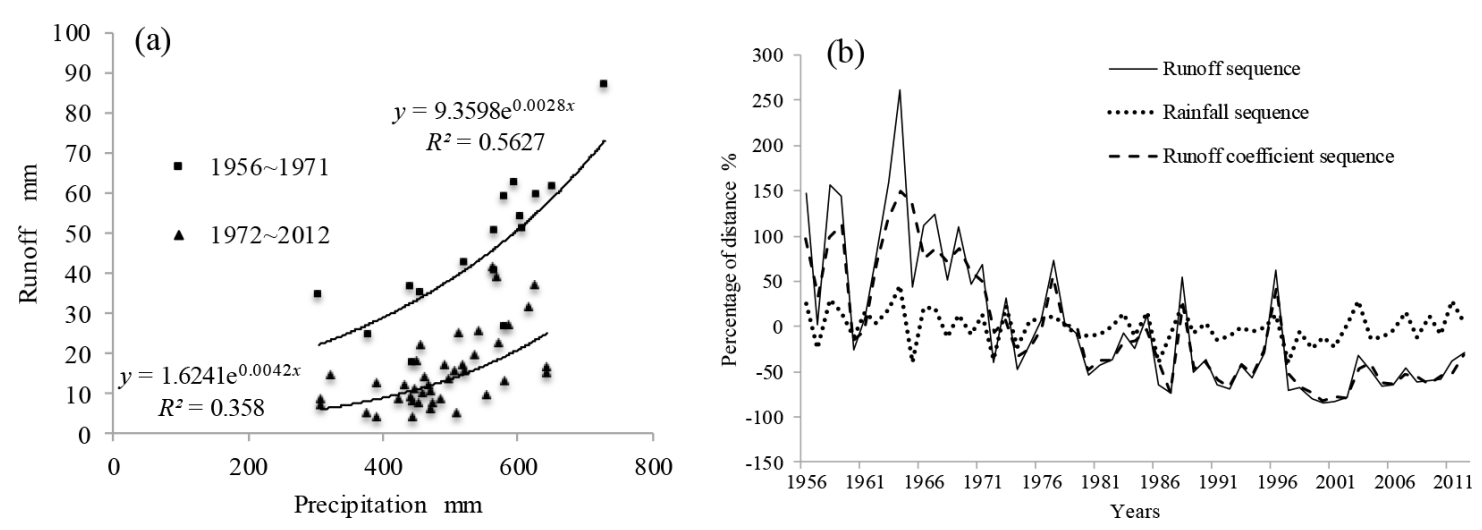

Figure 5. Variation of Precipitation Runoff and Departure from Hejin Station.

\subsection{Quantitative Analysis of the Impact of Climate Change on Runoff}

Table 2 shows the results of climate change on the impact of Fenhe into the Yellow River runoff calculation, Compared with the base period, the reduction of rainfall in the Fenhe River Basin from 1980 to 2012 resulted in an average annual reduction of $6.89 \mathrm{~mm}$, Which is 267 million $\mathrm{m}^{3}$. The decrease of the potential evaporation in the Fenhe River Basin in 1980 to 2012 resulted in an average annual increase of

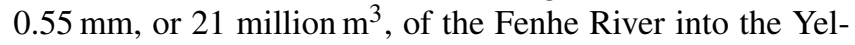
low River. The climate change in the Fenhe River Basin in 1980-2012 caused the Fen River into the Yellow River The average annual flow reduction of 246 million $\mathrm{m}^{3}$. The results of this study are basically consistent with those of Lan et al. (2012).

\subsection{Quantitative analysis of the relative contribution of the main influencing factors of runoff reduction in Fenhe River Basin}

Based on the quantitative analysis of the main influencing factors of Fenhe runoff sharply decrease, the contribution rate of the main influencing factors of Fenhe River runoff to the sharp drop in runoff is quantitatively described in the attribution segmentation frame of Fenhe River runoff. Table 3 shows the contribution rate of the main influencing factors of the runoff sharply decrease in the Fenhe River Basin from 1980 to 2012. The climate change causes the Fenhe runoff to decrease by an average of 246 million $\mathrm{m}^{3}$ per year and the contribution rate is $19.17 \%$. Among them, the reduction of the amount of Fenhe into the yellow runoff is averaged 267 million $\mathrm{m}^{3}$ per year, and the contribution rate is $20.81 \%$, The Fen River Basin potential evapotranspiration reduction caused by the temperature, wind speed and other meteorological factors, result in a Fenhe River runoff average annual increase of 0.21 million $\mathrm{m}^{3}$ and a contribution rate of $1.64 \%$. Human activities resulted in an average an- nual decrease of 1.066 billion $\mathrm{m}^{3}$ and a contribution rate of 83.09 per year. The contribution of groundwater exploitation to the runoff of the Fenhe River flows into the Yellow River was the highest, resulting in an average annual decrease of 386 million $\mathrm{m}^{3}$ and the contribution of $30.09 \%$. The coal mining is 334 million $\mathrm{m}^{3}$ per year, and the contribution rate is $26.03 \%$. reduction is 233 million $\mathrm{m}^{3}$, and the contribution rate is $19.17 \%$; land use is 105 million $\mathrm{m}^{3}$ and the contribution rate of $8.18 \%$; After 1980 the new evaporation caused by the new water conservancy project in Fen River Basin result in The Fen River runoff average reduction of 009 million $\mathrm{m}^{3}$ per year and the contribution rate of $0.07 \%$. The average annual runoff of the Fenhe River Basin decreased by 1.28 billion $\mathrm{m}^{3}$ per year from 1980 to 2012 . By the calculation of the main influencing factors respectively, the runoff influence by all the factors in 1980-2012 caused an average annual decrease of 1.13 billion $\mathrm{m}^{3}$, the difference is 29 million $\mathrm{m}^{3}$. Human activities are the main factors for the sharp drop in Fenhe runoff.

\section{Conclusions and discussions}

\subsection{Conclusions}

In this paper, based on the determination of the main influencing factors of the runoff of the Fenhe River flows into the Yellow River, the variation of the runoff series trend of the Hejin River in the Hejin River is analyzed by the hydrological variation diagnosis system. The annual runoff of the main site of the Fenhe River is significantly reduced, The runoff reduce by the rate of 0.158 million $\mathrm{m}^{3} \mathrm{a}^{-1}$; Fen Fenhe annual runoff has a mutation in 1971. Framework for constructing attribution segmentation of Yellow River runoff reduction in Fenhe River is united. In this framework, different methods is used to calculate the influence rate of climate such as rainfall, potential evapotranspiration and other human activity such as climatic factors and surface water exploitation, groundwater exploitation, land use on the Fen River runoff reduction and 
the quantity of runoff reduction. The results show that, compared with 1956-1971, the annual runoff of the Fenhe River is reduced by 1.283 billion $\mathrm{m}^{3}$ per year from 1956 to 1971 , and the human activity is the main factor in the Fenhe runoff decrease. The contribution rate of the main human factors to the runoff of the Fenhe River flows into the Yellow River dropped is $83.09 \%$. From large to small, the contribution factors is: groundwater exploitation $>$ coal mining $>$ surface water exploitation $>$ land use $>$ water conservancy. The contribution rate of the climate change to the runoff of the Fenhe River flows into the Yellow River decrease is $19.17 \%$, and the contribution rate of rainfall reduction is $20.81 \%$. The change of meteorological factors such as air temperature and wind speed increases the runoff of Fenhe River, The increase is 21 million $\mathrm{m}^{3}$ per year.

\subsection{Discussions}

Based on the principle of water balance, this paper calculates the change of rainfall and potential evaporation and the contribution rate of human surface, groundwater exploitation, land use, water conservancy project and coal mining to Fenhe River runoff decrease, and quantitative evaluate the influence of various factors on runoff from Fenhe River into Yellow River.

However, it is assumed that various factors are independent of each other, But in reality, various factors affect each other, and it is difficult to segment the various factors precisely. Therefore, the influence of the various factors calculated in this paper on the sharp drop in the yellow runoff is only estimated, Moreover, the calculation of the impact of various factors, there must be a repeated calculation part The accurate segmentation and calculation of the influence of various factors on the decrease of the runoff of Fenhe River into the Yellow River need further study.

Data availability. The data are not publicly accessible, because it comes from the the Yellow River Water Conservancy Commission, the state functional organ.

Competing interests. The authors declare that they have no conflict of interest.

Special issue statement. This article is part of the special issue "Innovative water resources management - understanding and balancing interactions between humankind and nature". It is a result of the 8th International Water Resources Management Conference of ICWRS, Beijing, China, 13-15 June 2018.

Acknowledgements. This paper is supported by the key special special project "the mechanism and trend prediction of water and sediment change in the the Yellow River basin"
(2016YFC040240203).

Edited by: Bo Pang

Reviewed by: two anonymous referees

\section{References}

Awan, U. K. and Ismaeel, A.: A new technique to map groundwater recharge in irrigated areas usinga SWAT model under changing climate, J. Hydrol., 519, 1368-1382, 2014.

$\mathrm{Du}, \mathrm{X}$. and Zhang, J.: Implementation of the ecological restoration of the Fenhe River Basin implementation of the central ecological civilization construction grand practice, Shanxi Water Conservancy, 32, p. 4, 2016.

Elfert, S. and Bormann, H.: Simulated impact of past and possible future land use changes on the hydrological response of the Northern German lowland "Hunte" catchment, J. Hydrol., 383, 245-255, 2010.

He, B., Miao, C. Y., and Shi, W.: Trend abruptchange, and periodicity of streamflow in the mainstream of Yellow River, Environ. Monit. Assess., 185, 6187-6199, 2013.

Jiang, S. H., Ren, L. L., Yong, B., Singh, V. P., Yang, X. L., and Yuan, F.: Quantifying the effects of climate variability and human activities on runoff from the Laohahe basin in northern China using three different methods, Hydrol. Process., 25, 2492-2505, 2011.

Jia, X. L., Kang, S. Z., Wei, X. M., et al.: Impacts of climate change and human activities on Yellow River Runoff in the Weihe River Basin, Journal of Northwest Agriculture and Forestry University, 35, 153-158, 2007.

Koster, R. D. and Suarez, M. J.: A simple framework for examining theinterannual variability of land surface moisture fluxes, J. Climate, 12, 1911-1917, 1999.

Ahn, K. H. and Merwade, V.: Quantifying the relative impact of climate and human activities on streamflow, J. Hydrol., 515, 257266, 2014.

Lan, Y. D., Kang, L. L., Dong, F. F., and Wang, Y. Z.: Effect of climatic change on runoff in Fenhe watershed, Journal of Water Resources \& Water Engineering, 23, 70-72+76, 2012.

Li, Z., Liu, W. Z., Zhang, X. C., and Zheng F.: Impacts of land use change and climate variability on hydrology in an agricultural catchment on the Loess Plateau of China, J. Hydrol., 377, 35-42, 2009.

Liang, L. X., Ren, Z. Y., Wang, L. X., and Niu, J. J.: Temporal and spatial characteristics of temperature changes in Fenhe River Basin, Journal of Arid Land Resources and Environment, 24, 5257, 2010.

Milly, P. C. D. and Dunne, K. A.: Macroscale water fluxes: 2. Water and energy supply control of their interannual variability, Water Res. Res., 38, 1206, https://doi.org/10.1029/2001WR000760, 2002.

Mu, X. M., Chiri, B., Zhang, L., Gao, P., Wang, F., and Zhang, X. P.: Variations of runoff and sediment and their responses to water conservancy and water conservation measures from the Yellow River estuary to Longmen Lake, Sediment Research, 02, 35-41, 2007.

Pereira, L. S., Allen, R. G., Smith, M., and Raes, D.: Crop evapotranspiration estimation with FAO56: Past and future, Agr. Water Manage., 147, 4-20, 2015. 
Sankarasubramanian, A. and Vogel, R. M.: Climate elasticity of streamflow in the United States, Water Resour. Res., 37, 17711781, 2001.

Wang, G. Q., Zhang, J. Y., Liu, J. F., and He, R. M.: Quantitative analysis of the impacts of climate change and human activities on river runoff, China Water Conservancy, 14, 55-58, 2008.

Wang, W. G., Shao, Q. X., Yang, T., and Luo, Y. F.: Quantitative assessment of the impact of climate variability and human activities on runoff changes: a case study in four catchments of the Haihe River basin, China, Hydrol. Process., 27, 1158-1174, 2013.

Xu, C. F., Dong, W. J., Li, Q., et al.: Analysis of the characteristics and causes of autumn water in the Weihe River Basin in recent 50 years, High Altitude Meteorology, 31, 409-417, 2012.

Xie, P., Chen, G. C., Lei, H. F., and Wu, F.: Diagnostic system of hydrologic variation, Journal of Hydroelectric Power Generation, 29, 85-91, 2010.

Yuan, Z. H., Yan, G., and Liu, Y. F.: Analysis of evolution law and influence factors of water and sediment in Fenhe River since 1950, Advances in Geographical Science, 05, 57-63, 2008.
Zeng, S. D., Xia, J., and Du, H.: Separating the effects of climate change and human activities on runoff over different time scales in the Zhang River basin, Stoch Env. Res. Risk A., 28, 401-413, 2014.

Zhang, G. S., Li, L., Shi, X. H., Xu, W. X., Dong, L. X., and Wang, Q. C.: Climate change in the upper reaches of the Yellow River and its influence on water resources in the Yellow River province, Progress of Water Science, 11, 277-283, 2000.

Zhang, X. C. and Wang, L.: Analysis of variation of natural runoff in the Yellow River, J. Hydrol., 5, 30-33, 2001.

Zhao, F. F., Zhang, L., Xu, Z. X., and Scott, D. F.: Evaluation of methods for estimating the effects of vegetation change and climate variability on streamflow, Water Resour. Res., 46, W03505, https://doi.org/10.1029/2009WR007702, 2010.

Zhao, Y., Hu, C. H., and Hu, S.: Facts Analysis of Significant Reduction in Runoff of Fenhe and Qinhe Basin, Water Resources and Power, 30, 31-34, 2012. 